\title{
Maternidad en los centros penitenciarios de Sinaloa, México. 2019
}

\section{Maternity in the penitentiary centers of Sinaloa, Mexico. 2019}

\author{
ANa Imelda CoRonel Cabanillas \\ Profesora Investigadora \\ Universidad Autónoma de Occidente, Sinaloa, México \\ ORCID: https://orcid.org/0000-0002-8113-9527 \\ Jorge Antonio Gastélum Escalante \\ Profesor Investigador \\ Universidad Autónoma de Occidente, Sinaloa, México. \\ ORCID: https://orcid.org/0000-0003-4714-3853
}

Recibido: $11 / 4 / 2019$

Aceptado: $14 / 10 / 2019$

doi: https://doi.org/10.20318/femeris.2020.5154

Resumen. El objetivo de este artículo es mostrar, desde una perspectiva de género, la historia de vida sobre la maternidad de las mujeres presas en los tres centros penitenciarios femeniles ubicados en el estado de Sinaloa, México.

El enfoque es cualitativo y de alcance exploratorio-descriptivo. Es un estudio de caso (Stake, 1995). La muestra es intencionada (Martínez, 2006) y se integró con 11 mujeres internas en los CECJUDE de Culiacán, Mazatlán y Ahome, Sinaloa, que cumplieron con alguno de los siguientes criterios de selección: ser madres de familia con hijos e hijas viviendo con ellas dentro del penal, o ser reclusas en condición de embarazo. En ambos criterios se consideró que, por la escasez de recursos económicos e inadecuadas condiciones de reclusión, a ellas se les dificulta aún más vivir su maternidad en prisión.

Para concretar el enfoque cualitativo se realizó un recorrido etnográfico, y para colectar la información de las historias de vida, se utilizó el instrumento respectivo según Taylor y Bogdan (1998).

En los discursos de las mujeres presas se detecta una percepción mayoritaria de deficiencia en el servicio médico, a la vez que manifiestan que existen instalaciones médicas, pero hay carencia de medicamentos, instrumental y de médicos especialistas. Tampoco hay programas para detectar y prevenir enfermedades crónico degenerativas propias de la mujer, como son el cáncer cervicouterino y de mama.

En cuanto a las condiciones para albergar a los menores de edad que viven al interior de los reclusorios femeniles de Sinaloa, con sus mamás presas, se observa que se carece de un área especial para que residan las internas con sus hijos e hijas. No hay servicios de guardería ni de educación básica; tampoco existen condiciones para una dieta alimenticia adecuada, ni atención médica pediátrica.

Palabras clave: Género, maternidad, embarazo, prisión, centros penitenciarios.

Abstract. This article's objective is to present, from a gender perspective, the life story regarding the maternity of female prisoners in the three female penitentiary centers located in the State of Sinaloa, Mexico. The approach is qualitative and exploratory-descriptive in scope. It is a case study (Stake, 1995). 
The sample is intentional (Martínez, 2006) and was integrated with 11 women who are inmates at CECJUDE at Culiacán, Mazatlán, and Ahome at the State of Sinaloa, who met one of the following selection criteria: to be mothers with children living with them within the criminal, or be inmates in pregnancy condition. In both criteria it was considered that, due to the scarcity of economic resources and inadequate conditions of confinement, they find it even more difficult to live their maternity at prison.

To specify the qualitative approach, an ethnographic visit was carried out, and to collect the information of life stories, the respective instrument was used according to Taylor and Bogdan (1998).

In inmates women testimonies it is detected a majority perception of deficiency in the medical service, at the same time they express that there are medical facilities, but there is a lack of medicines, instruments and medical specialists. Nor are there programs to detect and prevent chronic degenerative diseases of women, such as cervical and breast cancer.

Regarding the conditions to house the minors who live inside the female prison of Sinaloa, with their mothers imprisoned, it is observed that a special area is lacking for the inmates to reside with their children. There are no daycare or basic education services; there are no conditions for an adequate diet nor pediatric medical attention.

Keywords: Gender, maternity, pregnancy, prison, penitentiary centers.

\section{Introducción}

Desde el año 2000, de acuerdo con datos de World Prision Brief (WPB, 2018), la población penitenciaria del mundo creció $24 \%$. Por sexo, el porcentaje de mujeres que han ingresado a prisión aumentó 50\%, mientras que el de varones incrementó 18\%. En este aspecto, América Latina es una de las regiones con más mujeres presas en el mundo: de 2000 a 2015, la cifra aumenta $51.6 \%^{1}$ (CNN en español, 2016).

En lo que se refiere a las mujeres reclusas en México, el Censo Nacional de Gobierno, Seguridad Pública y Sistema Penitenciario Estatales (CNGSPSPE), realizado por el Instituto Nacional de Geografía y Estadística (INEGI, 2017), consigna que del año 2000 al 2016 «[...] se ha incrementado en un 56\%; crecimiento que ha sido mayor si se compara con el incremento en la población masculina de reclusos que creció $17 \%$ durante el mismo periodo» (p. 30).

No obstante, la población de mujeres reclusas constituye una minoría en la estadística del sistema penitenciario mexicano: sólo el 5\%, contra el 95\% de los hombres (INEGI, 2017), lo que ha provocado que las políticas y decisiones en los establecimientos de reclusión giren alrededor de las necesidades de los reclusos. Este aumento en la población penal de mujeres debería ser un factor para reconocer la necesidad de diseñar con mayor pertinencia las políticas que deben aplicarse al tratamiento de las mujeres internas en los centros penitenciarios, quienes conforman un grupo con necesidades y condiciones específicas, con frecuencia ignoradas por las autoridades; y que a pesar de la vigencia de la Convención Interamericana para Prevenir, Sancionar y Erradicar la Violencia contra la Mujer (1995) siguen siendo discriminadas -en este caso- por haber cometido un delito y ser recluida en un centro penitenciario por trasgredir la normas penales.

\footnotetext{
${ }^{1}$ Así lo asegura un informe de la Organización de los Estados Americanos (OEA) basado en información recogida por el Institute for Criminal Policy Research.
} 
En México hay una población que asciende a 9,705 mujeres presas en centros mixtos o femeniles (DNSP, 2017), un 45\% acusadas por distribución y transporte de drogas a pequeña escala (CNN en español, 2016); muchas de ellas tienen poca instrucción escolar, viven en condiciones de pobreza y son responsables del cuidado de personas dependientes.

Investigaciones como las de Bloom y Steinart (citados por Naredo, 2012, p. 3) destacan que la mayoría de las mujeres presas son madres, y que el encarcelamiento de una mujer con hijos e hijas bajo su responsabilidad «[...] pone en colisión diversos derechos y principios jurídicos de primera magnitud». Por su parte la Asociación Civil Reintegra (2017), en su diagnóstico anual precisa que en México el $88 \%$ de la población de mujeres reclusas tiene hijos e hijas, y que hay «[...] 417 mujeres en prisión que viven con 444 hijos e hijas en los centros de reinserción social donde cumplen con su condena» (DNSP, 2017, pp. 629-630).

Por esta relación con la maternidad, una de las principales preocupaciones de las reclusas, cuando ingresan a prisión, es el cuidado de sus hijos e hijas. Este rol social hace que la mujer sufra en mayor medida los efectos del encierro, ya que con frecuencia esto significa el rompimiento del vínculo familiar e incumplir con su responsabilidad social y económica que la tipifica y juzga como «[...] una mala madre o una enferma psicológica» (Antony, 2003, p. 20). Distinta situación presentan los hombres, quienes a pesar de todas las dificultades poseen una mayor facilidad para su propia manutención y cuentan con el apoyo de figuras femeninas que aseguran el contacto con los hijos e hijas.

El objetivo de este artículo es mostrar, desde una perspectiva de género, la historia de vida sobre la maternidad de las mujeres presas en Sinaloa; en particular las que están en condición de embarazo y las internas en los reclusorios sinaloenses que tienen sus hijos e hijas viviendo con ellas. Para el marco normativo de la investigación se analiza la legislación internacional, nacional y local que regula la situación de los infantes viviendo con sus madres en los centros penitenciarios, en tanto que para el marco teórico se recurre a especialistas en el tema.

El artículo está basado en una hipótesis fundada en la perspectiva de género que enfatiza las desigualdades en las condiciones para los hombres y mujeres. En este caso, el de las mujeres prisioneras, de quienes se supone que la discriminación por motivos de género en el contexto carcelario produce que se les segregue, lo cual dificulta su situación como mujeres presas embarazadas y con hijos e hijas viviendo con ellas en reclusión.

\section{La cárcel ¿qué es?}

La cárcel ha sido utilizada desde siempre en la cultura humana, trocándose su concepto desde la noción que la relacionaba con el pecado y la venganza, lugar de encierro y castigo, hasta constituirse en un medio para otorgar una nueva oportunidad a la persona reclusa, misma que al obtener su libertad estaría en condiciones de reinserción social (Méndez, 2014).

La Real Academia Española (RAE, 2018) define la prisión lo mismo como el local destinado a la reclusión, que igualmente la pena de privación de la libertad. Méndez (2014) la considera el último eslabón de un proceso de justicia penal que empieza con «la comisión 
del delito, prosigue con la instrucción del caso, el arresto de los sospechosos, su detención y el juicio penal que concluye con una sentencia condenatoria» (p. 6). De aquí las categorías de personas procesadas, juzgadas y condenadas.

En México y sus entidades federativas, las cárceles forman parte del sistema de justicia. Tanto sus ordenamientos como su estructura administrativa conforman el denominado sistema penitenciario. Su misión es «encerrar a aquellos individuos que han sido condenados por la comisión de algún delito» (ABC, 2017). Neuman (1994) añade que la cárcel es «un lugar [...] que acepta naturalmente la idea de contención y depósito de seres humanos acusados por delitos contra la propiedad» (p. 247).

En este sentido, Wacquant (1999) considera que la cárcel es el lugar donde terminan aquellas personas que, en su mayoría, no han tenido educación, trabajo, salud ni tipo alguno de garantía, lo que las convierte en seres proclives a la exclusión, la marginalidad y la violencia.

A su vez, Foucault (1983) afirma que, en la historia occidental, la prisión es la pena de las sociedades civilizadas; la ley ha definido a la institución-prisión como «la pena por excelencia», pieza esencial en el arsenal punitivo, aparato «de transformar a los individuos». Una cárcel, según este autor, es:

[...] un aparato disciplinario exhaustivo. En varios sentidos: debe ocuparse de todos los aspectos del individuo, de su educación física, de su aptitud para el trabajo, de su conducta cotidiana, de su actitud moral, de sus disposiciones; la prisión, mucho más que la escuela, el taller o el ejército, que implica siempre cierta especialización, es "omnidisciplinaria" (Foucault, 1983, p. 238).

En tanto escuela, la prisión es un plantel sin indulgencia; en tanto taller, es un establecimiento sombrío. Se trata de una institución cuyo cometido, el encierro, a la vez que la privación de la libertad cubre también la transformación técnica de los individuos. En ese sentido, el orden que guarda una prisión puede contribuir a regenerar a los condenados.

Así las prisiones trabajan para obligar a la gente a actuar de acuerdo con un orden imaginado, en primer lugar no admitiendo que ese orden es imaginado sino haciéndolo pasar por una realidad objetiva (Harari, 2018, pp. 124-132).

\section{Orientación teórica de las mujeres en prisión}

El análisis de la situación de las mujeres embarazadas y con sus hijos e hijas viviendo con ellas en los centros penitenciarios de Sinaloa, aparte de la visión sociológica del apartado anterior, se ha realizado desde una perspectiva de género, tomando en cuenta la historia de vida de estas mujeres en condición de prisión, quienes narran cómo la estructura, el funcionamiento y la dinámica de los reclusorios femeniles les niegan o limitan sus derechos, lo que les produce opresión, discriminación y les dificulta el proceso de la maternidad en este contexto. 
Lagarde (1996) señala que la perspectiva de género permite analizar y comprender las características que definen a las mujeres de manera específica, así como sus semejanzas y diferencias. Esta teoría, opuesta a la perspectiva androcéntrica, permite, según esta autora, investigar

[...] las posibilidades vitales de las mujeres y hombres en el sentido de sus vidas, sus expectativas y oportunidades, las complejas y diversas relaciones sociales que se dan entre ambos géneros, así como los conflictos institucionales y cotidianos que deben enfrentar y las maneras en cómo lo hacen (p. 15).

En este sentido, Lamas (1999) añade que el género se forma con el conjunto de normas y prescripciones que dictan la sociedad y la cultura sobre el comportamiento masculino y femenino. En el caso de esta investigación, la perspectiva de género es una herramienta de análisis, mediante la cual se describe la situación de inequidad de que son objeto las mujeres presas embarazadas y con hijos e hijas viviendo con ellas en los reclusorios de Sinaloa.

Al estudiar el sistema penitenciario femenino se observa que «[...] las mujeres tienen necesidades significativamente diferentes a las de los hombres en privación de libertad» (Barbaret, 2014, p.174), pero en contrario persiste la añeja discriminación por motivos de género que permea en dichos establecimientos: desde su estructura, operación y funcionamiento, que coloca a las mujeres en un entorno de segregación, lo cual produce una evidente desventaja en perjuicio de ellas.

Las mujeres reclusas sobreviven en las cárceles como un apéndice invisible (Cavazos, 2005). Así pasan a ser parte del sector oprimido (Freire, 1996), lo que provoca que las presas se sientan reprimidas, humilladas y ausentes, no visibles dentro de los centros penitenciarios; para corroborar esto, Azaola (citada por Noel, 2005, p. 29) explica que sólo basta observar el diseño arquitectónico de las prisiones, así como las normas, los reglamentos y los manuales que explican su funcionamiento, en los que no se toma en cuenta a la mujer: «cuando [esta] ingresa al ámbito penitenciario, la arquitectura le resulta absolutamente inadecuada y hostil» (p. 29).

Por lo general no se les brinda el trato ni las condiciones de estancia correspondiente a sus necesidades. La mayoría de los establecimientos que alojan población mixta y que fueron diseñados para el internamiento de varones, no cuentan con áreas especialmente destinadas a las mujeres, que garanticen una estancia digna y segura, tanto para ellas como para sus hijos e hijas que viven con ellas en los reclusorios (DNSP, 2017, p. 619).

Almeda y Bodelón (2007) consideran que el sistema carcelario es regido por una configuración androcéntrica que carece de una perspectiva igualitaria de género, y se fundamenta en presupuestos sexistas, producto de los estereotipos que fortalecen el rol tradicional de la mujer como cuidadora del hogar y crianza de los hijos e hijas. Tan es así que para las mujeres la ejecución de la pena carcelaria conlleva a que se violen sus derechos humanos, lo que contradice las obligaciones legales de las instituciones en el sentido de garantizar la protección y el ejercicio de tales derechos. 
En este aspecto, Antony (2001, p. 15) añade que la prisión para la mujer es un espacio genéricamente discriminador «[...] que se expresa en la desigualdad en el tratamiento que reciben, el diferente sentido que el encierro tiene para ellas, las consecuencias para su familia y la concepción que la sociedad les atribuye».

Así mismo, de acuerdo con Briseño (2006), Azaola (1996), Azaola y Yacamán (1996), en las cárceles para mujeres las internas sufren doble discriminación: la primera a consecuencia de su sexo, y la segunda producto de su estatus como reclusa. Cuando una mujer comete un delito rompe con el rol que la sociedad le ha encomendado (esposa obediente y madre sumisa). La sociedad en su conjunto reprocha con más dureza a la mujer que al hombre delincuente, porque «[...] al delinquir [la mujer] e ingresar en prisión, la familia queda abandonada y por lo tanto la mujer "incumple" con su obligación primordial» (Aguilera, 2010, p. 6).

Herrera (citada por Naredo, 2012) agrega que la mujer que delinque obtiene mayor reproche social que el hombre, pues no ha sabido comportarse conforme al rol que le ha asignado la sociedad; que por un lado es sumisa, pasiva, obediente, y por otro, mediadora en los conflictos familiares y representante de ese mismo orden. El inconsciente colectivo -dice Azaola- convierte a la mujer presa en «antimujer», en «madre desnaturalizada», y así tiene que soportar una doble estigmatización: primero como delincuente, pero además como mujer-delincuente, quien por esta transgresión es perseguida y castigada con un marcado moralismo familiar y social (Azaola, 2005).

En el contexto social, la mujer es «[...] presentada por los discursos dominantes como un ser unidimensional que solo puede ser madre» (Tuber citado por Saletti-Cuesta, 2008, p. 175). Con base en esta noción derivada del determinismo biológico, cuando la mujer incumple con este rol se acentúa su discriminación. Risso (2016) añade que la maternidad dentro de la cárcel es la oportunidad para reforzar la condena social de mala mujer y mala madre.

La perspectiva feminista, al revelar el carácter psico-socialmente construido de la maternidad, demuestra que el imaginario social sobre la misma está configurado por diversas representaciones que identifican la maternidad con la feminidad, proporcionando un ideal común para todas las mujeres (Rich, 1977). Por estas razones, Carrasco y Lombraña (2011) explican que cuando las mujeres son denunciadas por un delito que interpela su responsabilidad frente a sus hijos e hijas, lo que en verdad se lleva a juicio es el «amor maternal», «el instinto materno».

En el caso de las mujeres reclusas embarazadas, la Comisión Nacional de los Derechos Humanos (CNDH, 2015) ha informado que «[...] no se les brinda asesoramiento ni atención adecuada sobre su salud y dieta, ni tampoco sobre ejercicios físicos que les favorecerían en su proceso de gestación» (p. 10).

Por su parte, sobre las mujeres reclusas con hijos e hijas viviendo con ellas en la cárcel, Dormoy (1992) sostiene que con frecuencia les asaltan sentimientos de culpa, se sienten responsables de las carencias y problemas de sus infantes en prisión, lo que causa una intensa repercusión afectiva y emocional en el vínculo madre reclusa-hijo/a. Además, la CNDH (2017) señala que a pesar de que en los centros penitenciarios mexicanos viven 
niños y niñas mayores de tres años, estos infantes no reciben una educación adecuada ni un sano esparcimiento conforme con su edad, y no tienen acceso a guardería ni a educación básica.

La CNDH (2017) también ha reportado que a los menores de edad no se les proporciona una alimentación adecuada y suficiente. En relación con esto, resalta el tema de la salud de las mujeres en prisión, mismo que por lo general se aborda en función de su rol de madres, como si la salud de la mujer sólo fuera relevante al momento de procrear (Antony, 2003). La mayoría de los establecimientos visitados por la CNDH (2017) carecen de atención médica especializada hacia los padecimientos propios de la mujer, así como de los menores que viven con ellas, quienes en el mínimo de los casos son atendidos por médicos generales cuando lo requieren. Además, la preocupación constante de las mujeres presas por sus hijos e hijas les provoca ansiedad y estrés, por lo que «[...] abundan los trastornos calificados como nerviosos y la aplicación de tranquilizantes» (Salinas, 2014, p. 4).

El informe especial de la CNDH (2018) sobre las mujeres internas en los centros de reclusión de la república mexicana, muestra la preocupación de las condiciones de las reclusas embarazadas, así como los niños y niñas que viven con ellas; de ahí que este organismo conmina «[...] atender de manera sensible y respetuosa los derechos humanos de las hijos e hijas de dichas mujeres» (p. 38), para lo que es necesario se cumpla la obligación de privilegiar el derecho de estos infantes a convivir en adecuadas condiciones con sus madres privadas de libertad.

\section{Marco legal}

Para abordar la problemática de las mujeres presas embarazadas y con hijos e hijas viviendo con ellas, es necesario analizar instrumentos internacionales y las normas nacionales que instituyen las condiciones que el Estado debe salvaguardar para que estas mujeres gocen de condiciones dignas.

En el ámbito internacional, la Organización de las Naciones Unidas (ONU) creó las Reglas de las Naciones Unidas para el tratamiento de las reclusas y medidas no privativas de la libertad para las mujeres delincuentes, mejor conocidas como Reglas de Bangkok (2011). Su normativa está conformada por 70 reglas enfocadas en el objetivo de respetar los derechos y la salud de las mujeres presas y de sus hijos e hijas. A partir de la regla 7 se enfatiza la importancia de la atención médica y el apoyo psicológico para las reclusas.

Las reglas de Bangkok (2011) exhortan a los Estados a tener en cuenta los efectos en los niños y niñas causados por el encarcelamiento de sus padres, así como fomentar las buenas prácticas en relación con las necesidades y el desarrollo físico, emocional, social y psicológico de los infantes afectados por tal situación, cumpliendo así el principio del interés superior del niño; así también prohíbe sancionar a las mujeres embarazadas con el aislamiento del contacto familiar. A su turno, en la segunda parte de este conjunto de reglas se establece la protección especial para las mujeres embarazadas o lactantes, cerciorando que su alimentación y acceso a los servicios médicos sean los adecuados. 
La regla 52 de este mandato internacional marca que las mujeres privadas de la libertad que son madres, deben permanecer con sus hijos e hijas por lo menos hasta los seis años; y en caso de que se separe a los niños de sus madres y sean puestos al cuidado de familiares u otras personas se brindará a las reclusas el máximo posible de posibilidades y condiciones para reunirse con sus hijos e hijas, cuando ello redunde en el interés superior de éstos y sin afectar el orden público.

Por su parte, las Reglas Mínimas para el Tratamiento de los Reclusos (2015), mejor conocidas como reglas Nelson Mandela, en su medida 29 especifican que toda decisión de permitir que un niño permanezca con su madre en el penal se basará en el interés superior del niño, y que dado el caso se les deberán proporcionar servicios de guardería y de médicos especialistas con personal calificado, al tanto que advierten que los niños nunca deberán ser tratados como reclusos. Esta normativa (2015) determina también que en los reclusorios para mujeres deben existir instalaciones especiales para el tratamiento de las reclusas embarazadas, las que acaban de dar a luz y las convalecientes. Hasta donde sea posible, añade la norma, se tomarán medidas para que el parto se lleve a cabo en un hospital civil, pero si el niño nace en el centro penitenciario no deberá quedar por escrito en su acta de nacimiento.

El documento Principio y Buenas Prácticas sobre la Protección de las Personas Privadas de Libertad en las Américas, adoptado el 31 de marzo del 2008 por la Comisión Interamericana de los Derechos Humanos, enfatiza en la necesidad y el deber de tomar medidas para organizar guarderías infantiles con servicios educativos, pediátricos y de nutrición a los menores que viven con sus madres o padres en prisión, a fin de garantizar el bienestar superior de la niñez.

En el ámbito nacional, en México la legislación referente a los casos de las mujeres privadas de la libertad están fundamentados en la Constitución Política de los Estados Unidos Mexicanos (CPEUM, 2016), que en su artículo 1. establece que todas las personas gozarán de los derechos humanos reconocidos en esta constitución. Es decir, el Estado debe garantizar el respeto a la dignidad de las personas en prisión, en las mismas circunstancias aplicables a los individuos en libertad.

El artículo $18 .^{\circ}$ de esta carta magna (2016) establece que el sistema penitenciario mexicano se organizará sobre la base del respeto a los derechos humanos, el trabajo, la capacitación, la educación, la salud y el deporte, como medios para lograr la reinserción del sentenciado a la sociedad y procure no volver a delinquir. Las mujeres compurgarán sus penas en lugares separados de los de los hombres para tal efecto. Aquí es inevitable una crítica a la carta magna, puesto que solamente se refiere a la separación, pero no hace referencia a las necesidades y diferencias específicas en cuanto a la estancia de mujeres en los centros de reclusión y se hace caso omiso al cuidado que requieren las mujeres embarazadas y las que tienen sus hijos e hijas viviendo con ellas en prisión.

El marco legal de la CPEUM (2016) establece en su artículo $4 .^{\circ}$ el derecho a la protección de la salud para todas las personas, incluidas aquellas que se encuentren en reclusión.

El 20 de noviembre de 1989 se aprobó en México la Convención sobre los Derechos del Niño. En conformidad con este acuerdo, todos los infantes, incluyendo los que viven en pri- 
sión con sus madres, tienen derecho a no ser discriminados y no ser tratados como reclusos. Tal como sostiene Giacomello (2018), esta piedra angular del desarrollo internacional de los derechos humanos de la infancia, además de referirse a los derechos humanos intrínsecos de las personas -como el derecho a la vida, a la libertad, a la libre determinación y a la igualdad, entre otros-, elucidan el derecho de niñas y niños de gozar de protección específica.

Por su parte, la Ley Nacional de Ejecución Penal (2016) en su artículo $10^{\circ}$ establece los derechos de las mujeres privadas de su libertad, entre los que destaca que deberán recibir atención médica especializada, conservar la guardia y custodia de su hija o hijo menor de tres años, a fin de que estos permanezcan con la madre en el centro penitenciario, y reciban alimentación adecuada y saludable, educación inicial, vestimenta acorde con su edad y etapa de desarrollo, y atención pediátrica.

Además, en el ámbito del estado de Sinaloa, la Ley de Ejecución de las Consecuencias Jurídicas del Delito del Estado de Sinaloa (2013) dispone en el artículo 40. que los hombres y mujeres deben de estar por completo separados en los lugares de detención.

El decreto 970, del 21 de noviembre de 2013, y publicado en el Periódico Oficial No. 143, de fecha 27 de noviembre de 2013, en su Artículo 41 establece que los centros de ejecución de la pena de encarcelamiento deberán contar, en el conjunto de sus dependencias, con instalaciones y servicios idóneos de dormitorio, salud, enfermería, escuela, biblioteca, infraestructura deportiva y recreativa, trabajo, capacitación para el trabajo, educación, talleres, patios, cocina, comedor, locutorios, departamento de información al exterior, salas de visita íntima y, en general, todos aquellos que permitan desarrollar en ellos una vida en colectividad organizada y una adecuada clasificación de los internos, en relación con los programas de reinserción social» (p. 14).

Este decreto señala también que mientras no existan centros de maternidad, los Centros de Ejecución de las Consecuencias Jurídicas del Delito de Sinaloa (CECJUDE) deberán contar con dependencias especiales para la atención de las internas embarazadas y de las que han dado a luz; además se procurará que el parto se realice en un establecimiento asistencial ajeno al centro; y si el niño naciera en el establecimiento penitenciario no deberá constar esta circunstancia en su acta de nacimiento.

\section{Centros penitenciarios femeniles de Sinaloa}

En el caso de Sinaloa, este estado noroccidental de México dispone de tres de los 75 centros mixtos que albergan el 54\% de la población reclusa de mujeres en México. Con respecto a las condiciones de estos establecimientos penitenciarios, la Comisión Nacional de los Derechos Humanos, en la valoración anual que realiza sobre las condiciones de operatividad en ellos prevaleciente, le otorgó una calificación de 5.78 en promedio por los centros penitenciarios ubicados en los municipios de Culiacán, Ahome y Mazatlán, cifra por debajo del promedio nacional que es del 5.98 (DNSP, 2018).

Las principales causas de esta calificación en la operatividad de las prisiones femeniles en Sinaloa, se debe a la insuficiencia de instalaciones necesarias para su funciona- 
miento, falta de servicios para mantener la salud de las personas privadas de la libertad, y la insuficiencia para la realización de actividades laborales, de capacitación, educacionales y deportivas.

Los registros administrativos de los CECJUDE muestran que, hasta marzo del 2017, las mujeres presas eran 238, lo que representa el (3.65\%) del total de la población carcelaria, que ese año albergaba a 6,526 personas. Debido a esta menor cantidad numérica, la mujer reclusa en Sinaloa ha ocupado una posición secundaria en el sistema carcelario, igual que el resto de las mujeres en prisión de México. El informe del Diagnóstico Nacional de Supervisión Penitenciaria (DNSP, 2017) señala que:

[...] no se les brinda el trato, ni las condiciones de estancia correspondiente a las características y necesidades, en los cuales se ha evidenciado que la mayoría de los establecimientos que alojan población mixta y que fueron diseñados para el internamiento de varones, no cuentan con áreas especialmente destinadas a las mujeres que les garantice una estancia digna y segura, tanto para ellas como para sus hijos e hijas que viven con ellas en los establecimientos (p. 619).

En lo referido a las mujeres que son madres de familia y están presas en los centros penitenciarios de Sinaloa, se encuentra que -de acuerdo con los datos de la Encuesta Intercensal del Instituto Nacional de Estadística y Geografía (INEGI, 2015)- la gran mayoría de estas mujeres tienen hijos e hijas en una proporción de casi 9 de cada 10 (89.7\%). En la categoría de hijos e hijas, la tasa de fertilidad de las mujeres en prisión es de 2.7, por encima del conjunto de la sociedad sinaloense que es de un promedio de 1.7. Además, el $52,8 \%$ de las reclusas declararon tener más de tres hijos y/o hijas, lo que las ubica en la consideración de familias numerosas en México, puesto que, en general, las familias mexicanas indican un predominio de tres hijos y/o hijas.

\section{Marco metodológico}

Esta investigación es de enfoque cualitativo y de alcance exploratorio-descriptivo, aplicada al análisis de los tres centros penitenciarios femeniles ubicados en Sinaloa. Es un estudio de caso (Stake, 1995). El acceso al campo de investigación consistió en solicitar el ingreso a los penales, en la oficina del secretario de Seguridad Pública de Sinaloa, quien otorgó el permiso. Sin embargo, entrar a los penales propiamente tales, significó cumplir una serie de normas que tenían que ver incluso con la ropa de los investigadores y pasar por una serie de filtros de revisión. Sólo después de cumplir tales requisitos hubo acceso a los espacios destinados a las mujeres. Ya en contacto con ellas, hubo que gestionar la entrevista y establecer un rapport personal con cada una de ellas en las instalaciones que los directivos de los centros penitenciarios proporcionaron a los investigadores.

La muestra se integró con 11 mujeres internas en los CECJUDE de Culiacán, Mazatlán y Ahome, Sinaloa, que cumplieron con alguno de los siguientes criterios de selección: 
Tabla 1. Características de mujeres embarazadas y con hijos e hijas viviendo con ellas en los centros penitenciarios de Sinaloa.

\begin{tabular}{|c|c|c|c|c|c|c|c|c|}
\hline Entrevistada & Edad & $\begin{array}{c}\text { Estado } \\
\text { civil }\end{array}$ & $\begin{array}{c}\text { Grado } \\
\text { de estudios }\end{array}$ & $\begin{array}{c}\text { Situación } \\
\text { penal }^{1}\end{array}$ & Delito & $\begin{array}{l}\text { Situación } \\
\text { maternal }\end{array}$ & $\begin{array}{l}\text { Opinión sobre } \\
\text { el sistema } \\
\text { penitenciario } \\
\text { de salud }\end{array}$ & $\begin{array}{c}\text { Enfermedad } \\
\text { de la } \\
\text { reclusa }\end{array}$ \\
\hline Reclusa 1 & 22 & $\begin{array}{l}\text { Unión } \\
\text { Libre }\end{array}$ & $\begin{array}{l}\text { Licenciatura } \\
\text { Trunca }\end{array}$ & Procesada & Homicidio & $\begin{array}{l}\text { Un hijo } \\
\text { viviendo } \\
\text { con ella. }\end{array}$ & Deficiente & Ansiedad \\
\hline Reclusa 2 & 20 & Soltera & $\begin{array}{l}\text { Primer } \\
\text { año de } \\
\text { preparatoria }\end{array}$ & Procesada & $\begin{array}{l}\text { Intento de } \\
\text { homicidio }\end{array}$ & $\begin{array}{l}\text { Una hija } \\
\text { viviendo } \\
\text { con ella. }\end{array}$ & Deficiente & Hipertensión \\
\hline Reclusa 3 & 25 & $\begin{array}{l}\text { Unión } \\
\text { Libre }\end{array}$ & Secundaria & Procesada & $\begin{array}{l}\text { Autora intelectual } \\
\text { de homicidio }\end{array}$ & $\begin{array}{l}\text { Dos hijos } \\
\text { viviendo } \\
\text { con ella. }\end{array}$ & Deficiente & Ansiedad \\
\hline Reclusa 4 & 29 & $\begin{array}{l}\text { Unión } \\
\text { Libre }\end{array}$ & $\begin{array}{l}\text { Preparatoria } \\
\text { Trunca }\end{array}$ & Procesada & Robo & $\begin{array}{l}\text { Un hijo } \\
\text { viviendo } \\
\text { con ella. }\end{array}$ & Deficiente & Ansiedad \\
\hline Reclusa 5 & 27 & Casada & $\begin{array}{l}\text { Licenciatura } \\
\text { trunca }\end{array}$ & Procesada & Homicidio & Embarazada & Deficiente & Ansiedad \\
\hline Reclusa 6 & 22 & Casada & $\begin{array}{l}\text { Estudia la } \\
\text { secundaria }\end{array}$ & Procesada & Extorsión & Embarazada & Deficiente & Ansiedad \\
\hline Reclusa 7 & 33 & $\begin{array}{l}\text { Madre } \\
\text { soltera }\end{array}$ & $\begin{array}{l}\text { Licenciatura } \\
\text { trunca }\end{array}$ & Procesada & Fraude & Embarazada & Muy buena & Preclamsia \\
\hline Reclusa 8 & 28 & Casada & Licenciatura & Procesada & Robo de vehículo & Embarazada & Regular & Depresión \\
\hline Reclusa 9 & 24 & Casada & Secundaria & Condenada & $\begin{array}{l}\text { Delito contra } \\
\text { la salud }\end{array}$ & Embarazada & Buena & Ansiedad \\
\hline Reclusa 10 & 25 & $\begin{array}{l}\text { Unión } \\
\text { Libre }\end{array}$ & Preparatoria & Sentenciada & Robo & Embarazada & Deficiente & Depresión \\
\hline Reclusa 11 & 29 & Casada & $\begin{array}{l}\text { Secundaria } \\
\text { trunca }\end{array}$ & Sentenciada & $\begin{array}{l}\text { Delito contra } \\
\text { la salud }\end{array}$ & Embarazada & Deficiente & $\begin{array}{l}\text { Complicaciones } \\
\text { por el } \\
\text { embarazo de } \\
\text { alto riesgo }\end{array}$ \\
\hline
\end{tabular}

${ }^{1}$ En términos de la legislación pertinente, en México la situación penal de una persona reclusa se clasifica en procesada, condenada y sentenciada. «Procesada» significa que la persona está en proceso después de presentarse la demanda (carpeta) respectiva. A una persona «condenada», el juez ya le ha dictado su condena (servicio comunitario, años de cárcel, etcétera). «Sentenciada» significa que a la persona el juez le ha extendido el documento que consigna la sentencia. Ver Méndez (2014).

Fuente: elaboración propia

1. ser madres de familia con hijos o hijas viviendo con ellas dentro del penal, o

2. ser reclusas en condición de embarazo.

En ambos criterios se considera que, por la escasez de recursos económicos e inadecuadas condiciones de reclusión, a ellas se les dificulta aún más vivir su maternidad en la cárcel. Esta selección corresponde a una muestra intencionada tal como recomienda (Martínez, 2006, p. 12), con «[...] criterios necesarios o altamente convenientes para tener una unidad de análisis con las mayores ventajas con los fines que persigue la investigación».

Para concretar el enfoque cualitativo se utilizó el instrumento de la historia de vida, que según Taylor y Bogdan (1998) «[...] trata de aprehender las experiencias destacadas de la vida de una persona y las definiciones que le aplica a tales experiencias» (p. 102). Por eso 
el presente estudio consiste en historias de vida de tipo focal o temáticas (Aceves, 1996), en las que las narraciones «[...] se construyen enfatizando solo un aspecto problemático de la vida de los sujetos, es decir abordando solo un tema o cuestión en el curso de la vivencia de la vida del entrevistado» (p. 4). En este caso, son las mujeres presas embarazadas y con hijos e hijas viviendo con ellas, las que proveen de manera personal la información de su experiencia de vida sobre el proceso de la maternidad en las prisiones sinaloenses.

Entre las 11 mujeres presas del caso en estudio, siete estaban en condición de embarazo y cuatro tenían a sus hijos e hijas menores de edad viviendo con ellas en los centros penitenciarios. Las características de estas mujeres se describen en la Tabla 1. Los datos fueron proporcionados por ellas mismas al narrar su historia de vida en prisión.

\section{Hallazgos}

El estado de Sinaloa es uno de las entidades donde la legislación del sistema penitenciario permite la estancia de menores de edad con sus madres internas. Al momento de realizar el trabajo de campo había cuatro mujeres que tenían a sus hijos e hijas (una niña y tres niños) viviendo con ellas. Son las reclusas 1, 2, 3 y 4.

En las cárceles femeniles de Sinaloa es permitido que las madres, sin importar su situación jurídica dentro del sistema penitenciario, mantengan bajo su cuidado a sus hijos e hijas hasta los cinco años y once meses de edad, antes de ingresar a los estudios primarios (P. O., 2013). A continuación sus historias de vida, matizadas por la narrativa de los autores:

\section{Reclusa 1}

La primera imagen que un bebé mexicano percibió fue tal vez una celda del centro penitenciario de Culiacán, Sinaloa, donde su madre cumple una sentencia desde hace tres años. Esta mujer sinaloense fue apresada a la edad de 19 años por delito de homicidio. Vivía en unión libre y no contaba con estudios superiores a secundaria. Después de dos años calificados por ella como «difíciles» dentro de la institución carcelaria, se percató de que esperaba a su primer hijo. «Mi embarazo fue muy difícil, aquí no me daban los servicios que necesitaba para cuidar a mi bebé, no habían medicinas ni atención, por eso me ponía muy nerviosa. A los cuatro meses me dijeron que mi embarazo era de alto riesgo, pero seguía sin tener buenas atenciones. Mi hijo nació prematuro, de seis meses, pero sigue siendo igual de difícil mantenerlo y cuidarlo bien». En la actualidad el recién nacido vive con ella dentro de la penitenciaría y es visitado cada quince días por sus abuelos. «No tenemos buenas condiciones para convivir, ni para dormir, nada. Quisiera tener buena alimentación para mi hijo y que le dieran los cuidados médicos que necesita a su edad, pero aquí no los tengo».

\section{Reclusa 2}

A finales de 2016, el lugar más frecuentado por una joven de 18 años cambió de una escuela preparatoria en Mazatlán, Sinaloa, a un centro penitenciario en la misma ciudad para cumplir una sentencia por intento de asesinato. Relata: «Casi cumplía el año de que había en- 
trado a aquí, cuando me di cuenta de que estaba embarazada; era mi primer embarazo y pues yo tenía diecinueve años, no tenía a mis papás ni a nadie conmigo y tampoco tenía dinero... fue muy difícil». Sobre los servicios de salud de parte del centro penitenciario, la reclusa declara que son deficientes. Afirma: «Durante mi embarazo recibí muy malas atenciones por parte de la institución, no me atendían y eso que yo padezco de hipertensión, así que estaba preocupada de que algo le pudiera pasar a mi bebé y que aquí no me respondieran para nada. Pensé que, bueno, eran nueve meses, que me iba a aguantar; pero ya que nació mi hija, la situación no mejoró: aquí no hay instalaciones para ella, es difícil darle la alimentación adecuada y las consultas del pediatra que necesita». La reclusa posee un grado de estudios de nivel secundaria, debido a que desertó de bachillerato en su primer grado; sin embargo, desea continuar sus estudios y desarrollarse profesionalmente. Proyecta: «Planeo seguir estudiando cuando salga de aquí, me gusta la psicología, quiero trabajar para mi hija... pero también por mí».

\section{Reclusa 3}

El reclusorio para mujeres de Culiacán, Sinaloa, tiene como habitantes a un niño de tres años y un bebé de ocho meses, quienes nunca han cometido un delito, pero llaman a estas celdas su hogar. Su madre, una mujer mexicana de 25 años, cumple una sentencia por el delito de autoría intelectual de homicidio desde hace más de tres años, y dentro de las paredes de la cárcel concibió a su quinto hijo. Al respecto cuenta: «Cuando estaba embarazada me atendieron mal, los dos embarazos fueron difíciles porque no recibía una buena atención médica, fueron muy diferentes de mis otros embarazos, fuera de aquí». En la actualidad expresa que mantener a sus hijos se le dificulta debido a las condiciones del centro penitenciario: «Tengo a mis dos hijos más chicos viviendo conmigo, al de tres años y al de ocho meses, pero es muy difícil atenderlos bien aquí; por ejemplo, para alimentarlos es un problema porque no puedo cocinarles lo que un niño necesita o lo que le gusta, comen lo mismo que nosotras, aparte de que nunca ha venido ningún pediatra a revisar cómo están de salud, si están sanos... nada». Además, una de sus mayores preocupaciones es la falta de oportunidades educativas para sus hijos, sobre lo cual expresa: «Me preocupa mucho que aquí no haya escuelas para mis niños o una maestra que pueda enseñarles a leer y escribir, aunque está la opción de pagar una combi para el más grande, que lo lleve y lo traiga de algún kínder que esté cerca de aquí». Esta reclusa es madre desde los 16 años, cuando vivía en unión libre y no contaba con más estudios que un certificado de primaria. Además de los dos niños que viven con ella tiene tres hijos más, cuyas edades son ocho, seis y cinco años, quienes quedaron a cargo de la abuela de estos tras el encarcelamiento de su madre. «Dos veces por semana voy al reclusorio varonil a visitar a mi pareja; de él es mi niño, y ahí veo que están mejor los hombres que nosotras; cuando salga libre voy a poner un negocio de comida para sacar a mis hijos adelante y recuperar el tiempo perdido».

\section{Reclusa 4}

«En el penal de mujeres se batalla mucho, estamos en el olvido», son las palabras de una mujer mexicana de 29 años que arrulla a su hijo de dos años tras las rejas de una celda. Llevaba dos años cumpliendo una sentencia por el delito de robo en el centro penitenciario de Mazatlán, Sinaloa, cuando dio a luz a su segundo hijo, embarazo en el cual la institución 
penitenciaria le brindó servicios de salud -según dice- deficientes. «En el embarazo no me atendieron bien, no había medicinas y las citas eran cada tanto; yo ya había tenido un embarazo antes de entrar aquí, y pues sé que se necesita de otro tipo de atención, por eso me angustiaba mucho». Aun cuando el infante vive a diario con su madre, sólo dos veces por semana le es permitido visitar a su padre, quien se encuentra preso en el reclusorio varonil y vive en unión libre con la reclusa. «Además de la mala atención durante mi embarazo, darle una buena a mi hijo aquí dentro del penal es muy difícil, para empezar los trabajos que tenemos son mal pagados y lo poco que gano no me alcanza para una buena alimentación para mi niño y aún menos puedo ofrecerle algo a mi otro hijo al que cuida mi mamá. La libertad la quiero para volver a estar con mi hijo, con los dos juntos, quiero volver a tener una familia completa».

En cuanto a las condiciones para albergar a los menores de edad que viven al interior de los reclusorios femeniles de Sinaloa con sus mamás presas, en la observación etnográfica se advierte -y lo ratifican las reclusas en sus relatos- que el reclusorio carece de un área especial para que residan las internas con sus hijos e hijas, por lo que tienen que convivir con el resto de las reclusas. No hay servicios de guardería ni de educación básica; tampoco existen condiciones para una dieta alimenticia adecuada, ni atención médica especializada como los cuidados y vigilancia del pediatra.

Uno de los problemas que refieren enfrentar las mujeres presas en Sinaloa son los relacionados con la salud, que de acuerdo con Salinas (2014) son ocasionados por el nerviosismo, la ansiedad y el estrés por la situación de vulnerabilidad en la que se encuentran sus hijos e hijas.

En el recorrido -de corte etnográfico; esto es: observacional, de registro y descripción- que se realizó en los tres centros penitenciarios femeniles de Sinaloa, se constató que existen, de manera precaria, instalaciones para la atención médica de las mujeres, pero carecen de personal médico, hay escasez de medicamento y no cuentan con instrumental médico ni especialistas como ginecólogos para atender las necesidades específicas de las reclusas, lo cual contradice los principios de las Reglas de Bangkok (2011) y los derechos inherentes al ser humano estipulados por la ONU (2004), y que en México están garantizados por la CPEUM (2016) en el artículo $1^{\circ}$.

Según esto, la atención a la salud debe ser aún mejor cuando una mujer está en condición de embarazo, como es el caso de las siete reclusas en Sinaloa entrevistadas en este estudio de caso. Aquí sus historias de vida:

\section{Reclusa 5}

Una joven mexicana estudiaba - dice- con dificultades una licenciatura en diseño gráfico en Sinaloa, México. No obstante, un evento cambió su hogar y su butaca de un aula universitaria por una celda en el centro penitenciario de Culiacán. En 2012 fue apresada por el delito de homicidio, y separada de su esposo y su hijo, de apenas un año de edad. «Tuve a mi primer hijo a los veinte años, pero mis papás no quisieron que dejara la escuela, me apoyaban en todo lo que podían para que yo siguiera estudiando la carrera y me ayudaban a cuidar a mi hijo porque mi esposo trabajaba todo el día y tampoco podía hacerse cargo de 
él». Fue procesada y estaba en el quinto año dentro de la institución carcelaria, cuando se percató de que esperaba a su segundo hijo: «Durante mi embarazo el penal no me ha atendido bien, yo padezco ansiedad y el saber que no estoy cuidando a mi hijo como debería por la falta de servicios me pone muy mal». Además, su situación económica la inquieta al pensar en el porvenir de su hijo: «No tengo apoyo, me siento sola y en el penal es muy difícil; no hay atención médica ni buena comida, y conseguir un trabajo es otro problema. A mi otro hijo lo cuida mi mamá, allá en Guasave; por eso es que no pueden venir seguido a visitarme». En la actualidad tiene ocho meses de embarazo; no obstante, la reclusa no tiene comunicación con su pareja ni recibe visitas conyugales.

\section{Reclusa 6}

Una joven mexicana, originaria de Mazatlán, Sinaloa, vivió dos momentos considerados por ella «tormentosos», a lo largo de su vida: el primero fue a los quince años cuando se vio obligada a revelar a su familia que esperaba a su primer hijo y abandonaría sus estudios de secundaria para casarse con el padre del bebé; el segundo momento fue cuando los oficiales de seguridad estatal irrumpieron en su hogar para apresarla junto con su esposo y madre, trasladándola al centro penitenciario de su ciudad. Tenía casi veinte años cuando fue sentenciada por el delito de extorsión. Dentro de las celdas del penal asiste a clases de educación secundaria y trabaja como ayudante en el reclusorio para solventar sus gastos; sin embargo, su situación económica es precaria. «Aunque me siento segura en la institución, encontrar trabajo aquí es muy difícil y el sueldo que tengo no me alcanza ni para cubrir mis gastos básicos».

Su situación se complicó al cumplir dos años dentro del penal y percatarse de que esperaba a su tercer hijo. «Mi mamá está aquí conmigo, ella me ayuda, está al pendiente de mí y de mi embarazo. Dentro de lo que cabe no estoy tan sola como otras de mis compañeras, que también esperan un hijo, pero aun así mi mamá no puede ayudarme mucho porque faltan atenciones médicas, que un doctor me atienda y que revise que todo está bien con mi bebé, pero aquí el penal no nos lo trae». Además, desde el inicio del embarazo no ha tenido contacto con su esposo, quien está recluso en el penal varonil. En la actualidad sus hijos, de siete y cuatro años de edad, son cuidados por su tía y visitan a su madre y abuela por lo regular acompañados de familiares y amigos de las reclusas.

\section{Reclusa 7}

Dos niños sinaloenses esperan ansiosos -así se les observa y lo comentan- el nacimiento de su nuevo hermano en fechas próximas. No obstante, se diferencian de cualquier otra familia mexicana porque este bebé nacerá dentro del centro penitenciario de Mazatlán, Sinaloa, donde su madre es procesada por el delito de fraude. La reclusa es una mujer de 33 años de edad, que vivía como madre soltera junto a su padre y sus dos hijos, de doce y un año de edad. «Como no tenía título universitario, trabajaba pues en el comercio, vendiendo, para cubrir los gastos de mis hijos y del que estaba esperando. El día en que me trajeron aquí al penal tenía ya cinco meses de embarazo, pero las mismas impresiones, los traslados y la gente de aquí que me trataron casi como si no estuviera esperando un hijo, me complicó el embarazo». Relata que durante el proceso penal su estado de salud se vio afectado, lo que ocasionó que se encuentre en constante monitoreo de preclamsia (presión arterial alta cró- 
nica antes y durante el embarazo). A pesar de que la reclusa declara haber recibido atención médica buena por parte de la institución penitenciaria, durante los cuatro meses de embarazo que vivió en el penal su porvenir y el de su bebé le preocupan debido a su situación económica. «No sé qué voy a hacer cuando mi bebé ya nazca. Me han atendido bien con el problema que tengo de preclamsia, pero aquí en el penal es muy difícil encontrar trabajo. No sé con qué voy a alimentar bien a mi hijo o darle lo que necesita como sus cuidados médicos y estudios». En la actualidad la reclusa es visitada constantemente por sus hijos, quienes quedaron a cuidado del padre y la hermana de aquella.

\section{Reclusa 8}

Hace menos de un año, una mujer mexicana se levantaba temprano a diario para atender a decenas de niños como profesora en un plantel de educación preescolar en Culiacán, Sinaloa; hoy es una reclusa en el centro penitenciario de la misma ciudad. Tenía 28 años de edad y una hija de cinco cuando fue apresada junto con su esposo por delito de robo de vehículo. Al cumplir cuatro meses en el penal, dice haberse percatado de que daría vida a otro niño, pero esta vez dentro de las celdas penitenciarias y en compañía de su esposo, a quien visita en su «carraca ${ }^{2}$ dos veces por semana. Narra: «En el penal me atienden... regular, ni bien ni mal; lo que me preocupa es cuando nazca mi niño, ¿con qué lo voy a mantener? No tengo trabajo para darle una buena alimentación, servicios médicos... una buena calidad de vida en la medida que sea posible aquí dentro». Aunado a lo anterior, esta reclusa padece un trastorno psicológico de depresión causado por la ausencia de su hija. Explica: «Con mi hija sólo me comunico por teléfono, me duele mucho no verla, le cuento que ando de viaje y que pronto regresaré; jamás le diré que estoy presa porque no quiero que pise la cárcel, ni un pie aquí, quiero que siga creyendo que su papá y yo estamos viajando».

\section{Reclusa 9}

Hace cinco años y medio una mujer mexicana de edad de 19 años, originaria de Nogales, Sonora, cuidaba a su hija de cuatro años en su hogar; hoy la abraza en una celda los días de visita en el centro penitenciario de Mazatlán, Sinaloa. De su narración deriva que se convirtió en esposa y madre adolescente a la edad de 15 años, razón por la cual abandonó sus estudios al culminar el grado secundario; se dedicaba a su hogar y al cuidado de su hija como ama de casa, hasta que la necesidad económica la impulsó a cometer el error -reconoceque la separaría de su familia: prestarse como transportadora de droga. Al llegar a Sinaloa las autoridades la descubrieron y fue trasladada al centro penitenciario de Mazatlán, donde fue sentenciada por delito contra la salud. «Como mi familia vive en Nogales, no pueden venir a visitarme seguido, no tenemos el dinero para pagar tanto traslado. Tuve que ver a mi hija sólo unas veces al año mientras crecía. Cuando ella cumplió nueve, más o menos por esas fechas, me di cuenta de mi embarazo y aunque aquí me han atendido bien, no puedo dejar de pensar en lo que le espera a mi hijo cuando nazca: ¿qué vida le voy a dar aquí lejos de mi familia, sin dinero, sin un espacio adecuado para él? Para distraerme y calmar la ansiedad estoy trabajando como ayudante aquí en el penal, pero aun así me preocupo mucho».

${ }^{2}$ Carraca: despectivo de cárcel; aplica también a las celdas. 


\section{Reclusa 10}

Tenía veinte años y una hija recién nacida cuando fue apresada por el delito de robo y sentenciada en el centro penitenciario de Los Mochis, Sinaloa. Antes de ser trasladada a la institución penal trabajaba como empleada doméstica en su ciudad, vivía en unión libre y contaba con estudios de bachillerato. «Llevo en el penal cinco años y medio. Cuando me apresaron sufrí una depresión muy fuerte debido a que me separé de mi familia, el haber dejado a mi niña recién nacida y estar aquí sola me afectó mucho. Trato de ganar un poco de dinero trabajando, así que corto, tiño el pelo y pongo uñas a las demás compañeras del penal, pero el sueldo es muy poco y no me alcanza para cubrir mis gastos básicos». Aunado a esta problemática situación -así considerado por ella misma-, esta joven reclusa tiene medio año de embarazo, lapso durante el cual «he recibido atenciones muy malas por parte de la institución, los servicios de salud son malos, al igual que la dieta... además de que he tenido un solo chequeo por un médico en estos seis meses. Cuando salga libre no sé qué voy a hacer, no sé qué me prepara (sic, tal vez quiso decir depara) el futuro, pero estoy segura de que me voy a dedicar a mi familia y la voy a sacar adelante, tal vez trabaje de estilista, no sé, pero les voy a dar una mejor calidad de vida».

\section{Reclusa 11}

Una mujer originaria del estado de Michoacán, México, se convirtió en madre a los dieciocho años de edad, y a los veintiséis en reclusa en el centro penitenciario de Los Mochis, Sinaloa. Relata que estaba casada y que trabajaba como empleada doméstica, al no contar con estudios más allá del grado secundario. Por la precariedad de sus ingresos decidió migrar a Sinaloa como portadora de droga; al llegar a ese estado fue apresada y sentenciada por delitos contra la salud. Después de casi tres años de habérsele privado la libertad, se reunió con su esposo en visitas conyugales; éste había estado preso durante años. «Con el paso del tiempo me percaté de que esperaba a mi segundo hijo, durante el embarazo la institución penitenciaria me ha dado pocas atenciones de salud, además de que los servicios son malos, llevo seis meses de embarazo y sólo me han checado una vez, todo eso provocó que mi embarazo sea de alto riesgo». La reclusa manifiesta que le preocupa la salud de su hijo y que se inquieta ante las dificultades económicas que tendrá que afrontar cuando éste nazca. «Me preocupa mucho el niño que estoy esperando, tanto ahora mismo como ya cuando nazca, no sé si aquí puedo darle una buena vida. Cuando salga libre voy a trabajar para mis hijos, para que estudien; quiero que salgan adelante y tengan una buena vida, honrada y estable».

La mayoría de las mujeres embarazadas que están en situación de cárcel en los centros penitenciarios de Sinaloa califican el servicio de salud como deficiente: falta atención y personal médico especializado y el medicamento es insuficiente.

Casi todas las reclusas informaron que padecen problemas psicológicos como ansiedad y depresión causadas por las circunstancias adversas que han tenido que vivir al interior de los centros penitenciarios, lo cual ha afectado su estado emocional. Alguna presenta preclamsia, una enfermedad somática. 
Lamentan que viven con dureza su situación familiar, ya que carecen de las visitas y el apoyo de parte de ellos.

Los testimonios de las mujeres embarazadas que están presas en Sinaloa visibilizan una escasa formación educativa y precariedad económica y laboral, además de que las oportunidades de trabajo al interior de los reclusorios son escasas y poco cualificadas.

Con base al análisis anterior, se puede señalar que las condiciones en que se encuentran las reclusas en condición de embarazo en los centros penitenciarios de Sinaloa, no cumplen con las normas nacionales e internacionales respecto a una estancia digna contenidas en las Reglas Mínimas para el Tratamiento de los Reclusos (2015) y en los principios de las Reglas de Bangkok (2011) referidos en el marco legal de este artículo.

Como se señaló al inicio de este trabajo, la hipótesis de esta investigación está fundada en la perspectiva de género que enfatiza las desigualdades en las condiciones para los hombres y mujeres. En este caso, las mujeres prisioneras embarazadas o con hijos e hijas viviendo con ellas en los centros penitenciarios de Sinaloa confirman, a través de sus testimonios, que se encuentran en una situación vulnerable y de discriminación debido a la escasez de servicios médicos especializados, atención adecuada para los infantes que viven con ellas y oportunidades laborales bien remuneradas al interior de los reclusorios.

\section{Conclusiones}

La teoría aquí revisada considera la cárcel como lugar de privación de la libertad. Para Foucault (2008) se trata de una institución cuyo cometido es la transformación técnica de los individuos. En ese sentido, el orden que guarda una prisión puede contribuir a regenerar a los condenados. Eso desde el punto de vista de la teoría sociológica.

Es de considerarse que los derechos, aunque sean imaginarios, como afirma Harari (2018), son deber ser sin correspondencia consecuente en el ser.

Desde los datos empíricos de esta investigación, como deriva de la Tabla 1, cinco de las mujeres reclusas en Sinaloa declararon ser casadas, cuatro afirmaron vivir en unión libre, una se reconoce madre soltera, y la decimoprimera restante se proclamó soltera. Una de ellas es licenciada, tres dejaron trunca su licenciatura, una cursó el bachillerato y dos declararon haberlo truncado, dos terminaron la secundaria mientras una la dejó empezada y otra más está cursándola. Tres cometieron homicidio mientras una está siendo procesada por intento de cometer esa misma falta, tres perpetraron algún robo, dos están presas por delitos contra la salud, una por extorsión y otra por fraude.

En cuanto a su salud y la atención que han recibido, más de la mitad padecen de ansiedad, casi una quinta parte sufren depresión, una preeclampsia, otra hipertensión y otra más padece complicaciones por embarazo de alto riesgo. En síntesis, todas requieren atención de su salud, somática o psíquica, no obstante la mayoría de ellas opinan que los servicios médicos en los centros penitenciarios son deficientes.

Eso refleja que una es la norma y otra la realidad. Una de las violaciones más frecuentes que enfrentan las mujeres en prisión son las relacionadas con su derecho a la 
salud. En esta investigación las reclusas embarazadas informaron que para recibir atención médica tuvieron que haber esperado meses para poder ser atendidas. La misma situación prevalece con los hijos e hijas de las mujeres reclusas: de acuerdo con sus testimonios, carecen de los servicios de salud y de los medicamentos para curarlos cuando se les enferman, lo que viola el principio de interés superior de la niñez, así como el Tratado de Bangkok.

Es de recalcarse que la mayoría de las mujeres presas en Sinaloa califican el servicio médico como deficiente, a la vez que manifiestan -y se observa- que existen instalaciones médicas, pero hay carencia de medicamentos, de instrumental y de médicos especialistas. Tampoco hay programas para detectar ni prevenir enfermedades crónico degenerativas propias de la mujer, como son el cáncer cervicouterino y de mama.

En los penales femeniles de Sinaloa, el Estado no está brindando políticas públicas que cumplan con la satisfacción de las necesidades mínimas como la salud, alimentación y educación, a pesar de que es un mandato constitucional. Las mujeres que han tenido hijos e hijas en prisión señalan que las condiciones ponen en riesgo sus vidas y las de sus bebés;

La manera como funcionan en su cotidianeidad estos establecimientos contradice los derechos estipulados por la legislación internacional, nacional y local, que resguardan las condiciones de vida en recintos destinados a mujeres y al cuidado de sus hijos e hijas. Estos menores que viven con sus madres presas en Sinaloa, no gozan plenamente de sus derechos humanos, ya que carecen de un régimen alimenticio especializado para su edad, no tienen las condiciones para recibir la educación básica dentro del reclusorio; además de que no se les brinda atención oportuna y especializada a su salud.

Después de realizar el análisis de los resultados en esta investigación y tras advertir las deficiencias y las privaciones que padecen las mujeres presas en condición de embarazo y con hijos e hijas viviendo con ellas en prisiones de Sinaloa que vulneran los derechos humanos consagrados en los preceptos constitucionales, convenios y acuerdos internacionales, se recomienda:

1. Que se cumplan las recomendaciones internacionales y las leyes nacional y local respectivas.

2. Que, de acuerdo con eso, las mujeres reclusas en los centros penitenciarios de Sinaloa reciban un trato digno y respetuoso en su salud mediante programas médicos generales y especializados, así como a los hijos e hijas que las acompañan.

3. Que al interior de los reclusorios se realicen campañas de salud para detectar y prevenir enfermedades crónico-degenerativas propias de la mujer, como son el cáncer cervicouterino y de mama.

4. Que se lleven a cabo programas para el cuidado de las enfermedades y los trastornos de salud mental que padecen las internas como consecuencia del encierro que viven.

5. Que se les proporcione una dieta alimenticia adecuada a las mujeres reclusas embarazadas, a las madres en estado de lactancia y a los menores de edad que estén viviendo con ellas. 
6. La creación de instalaciones y programas educativos dirigidos a los infantes, llevados a cabo por personal educativo especializado, en los centros penitenciarios para atender a los hijos e hijas que se encuentran viviendo con ellas.

7. Propiciar las condiciones, y un lugar digno específico, para que las reclusas que tienen a sus hijos e hijas viviendo con ellas convivan con ellos el mayor tiempo posible.

\section{Bibliografía}

ABC. (2017). Tu diccionario hecho fácil., [En línea]. Disponible en https://www.definicionabc.com/derecho/prision.php

ACEVES, JORGE (1996). Historia oral e historias de vida. Teoría, método y técnicas. Una bibliografía comentada. México: CIESAS.

AGUILERA, MARGARITA (2010). Mujer y pobreza en Revista Derechos Humanos, N 1 , Andalucía: APDHA. [En línea] Recuperado en https://www.apdha.org/webanterior/ media/1mujer_pobreza.pdf

ALCOCER, JENNIFER (2018). El 88\% de reclusas en México es mamá; 417 tiene a sus hijos en su celda, México. [En línea] Recuperado en file:///F:/MUJERES\%20E\%20HIJOS\%20 EN\%20PRISIÓN/REINTEGRA\%202017.htmlAsociación Civil Reintegra (2017). Diagnóstico anual. [En línea] Recuperado en http://reintegra.org.mx/

ALMEDA, ELISABET y BODELÓN, ENCARNA (2007). Mujeres y castigo: un enfoque sociojurídico y de género, Madrid: Instituto Internacional de Sociología Jurídica de Oñati Dykinson.

ANTONY, CARMEN (1998). Mujer y cárcel: rol genérico en la ejecución de la pena, Criminalidad y criminalización de la mujer en la región andina, Caracas: Nueva Sociedad.

ANTONY, CARMEN (2003). Violencia contra las mujeres privadas de libertad en América Latina. México: Comisión de Derechos Humanos del Distrito Federal.

AZAOLA, ELENA (1996). El delito de ser mujer. México: Plaza y Valdés.

AZAOLA, ELENA (2005), «Las mujeres en el sistema de justicia penal y la antropología a la que adhiero» en Cuadernos de Antropología Social. Núm.22. Facultad de Filosofía y Letras, Universidad de Buenos Aires, pp.11-26. [En línea] Recuperado de www.scielo.org.ar/pdf/cas/n22/n22a02.pdf.

AZAOLA, ELENA y CRISTINA YACAMÁN (1996). Las mujeres olvidadas. México: El Colegio de México.

BARBARET, ROSEMARY (2014). Women, crime and criminal justice, A global enquiry. New York: Routledge.

BRISEÑO, MARCELA (2006). Garantizando los derechos humanos de las mujeres en reclusión. México, Instituto Nacional de las Mujeres (INMUJERES) y Programa de las Naciones Unidas para el Desarrollo (PNUD).

CARRASCO, MORITA y LOMBRAÑA, ANDREA (2011). Sobre la construcción jurídica del 'ser madre' en dos procesos penales. Avá. Revista de Antropología, 23, 119-137 [En línea] http://www. redalyc.org/pdf/1690/169039923005.pdf 
CAVAZOS, IRMA (2005). Mujer, etiqueta y cárcel. Aproximaciones al sujeto mexicano femenino. México, UAM-INACIPE.

CNN en Español, (2016). A qué se debe el aumento de mujeres presas en América Latina. México. [en línea] Recuperado en file://F:/MUJERES\%20E\%20HIJOS\%20EN\%20 PRISIÓN/CNN\%20EN\%20ESPAÑOSL,\%202016.html

COMISIÓN NACIONAL DE DERECHOS HUMANOS. (CNDH). (2017). Diagnóstico Nacional de Supervisión Penitenciaria, México: CNDH.

CONSTITUCIÓN POLÍTICA DE LOS ESTADOS UNIDOS MEXICANOS. México (2016). [En línea] Recuperado de http://www.sct.gob.mx/JURE/doc/cpeum.pdf

CONVENCIÓN SOBRE LOS DERECHOS DEL NIÑO (2006). España: UNICEF [En línea] Recuperado en http://www.un.org/

DORMOY, ODILE (1992). L'enfant etla prison. In: Enfance. Tome 46, №3,pp. 251-263. [En línea] Recuperado en https://www.persee.fr/doc/enfan_0013-7545_1992_num_45_3_2020

FOUCAULT, MICHEL (1983). Vigilar y castigar. México: Siglo XXI.

FREIRE, PAULO (1996). Política y educación. México, Siglo Veintiuno editores.

GIACOMELLO, CORINA (2018). Niñas y niños que viven en prisión con sus madres. Una perspectiva jurídica comparada, México: Suprema Corte de la Justicia de la Nación.

HARARI, YUVAL (2018). De animales a dioses. Breve historia de la humanidad. México: Debate.

INSTITUTO NACIONAL DE ESTADÍSTICA Y GEOGRAFÍA (2017). Estadística sobre el sistema penitenciario estatal en México, México, INEGI.

INSTITUTO NACIONAL DE ESTADÍSTICA Y GEOGRAFÍA. Encuesta Intercensal (2015). [En línea] Recuperado en https://www.inegi.org.mx/

INSTITUTO NACIONAL DE LAS MUJERES (1995). Convención Interamericana de Belén do Pará, para prevenir, sancionar y erradicar la violencia contra la mujer. México: Inmujeres.

LAGARDE, MARCELA (1996). «El género» Fragmento literal; la perspectiva de género, en Género y Feminismo. Desarrollo Humano y democracia. España: Horas.

LAMAS, MARTA (1999). Género, diferencia de sexo y diferencia sexual en ¿Género?, Debate Feminista, Año 10, Vol. 20, México, edición de octubre.

LEY NACIONAL DE EJECUCIÓN PENAL (2016). México: Cámara de Diputados del Congreso de la Unión [En línea]. Recuperado de http://www.secretariadoejecutivo.gob.mx/ docs/pdfs/normateca/Leyes/Ley\%20Nacional\%20de\%20Ejecuci\%C3\%B3n\%20 Penal.pdf

MARTÍNEZ, MIGUEL (2006). La investigación cualitativa, síntesis conceptual, Lima: UNMSM. MÉNDEZ, LENIN (2014). Derecho penitenciario. México: Oxford University Press.

NAREDO, MARÍA (2012). Reclusas con hijos/as en la cárcel. Universidad de Barcelona: v/ lex. [En línea] Recuperado en ww.ucipfg.com/Repositorio/EPDP/Curso\%20002/ bloque_academico/Unidad04/Reclusasconhijos-as.pdf

NEUMAN, ELÍAS (1994). Victomología y control social: las víctimas del sistema penal. Buenos Aires: Cárdenas.

NOEL, MARÍA (2003). «Mujer y cárcel en América Latina». En violencia contra las mujeres privadas de libertad en América Latina. Memorias del seminario-taller. México, 
Comisión de Derechos Humanos del Distrito Federal (CDHDF), Fundación para el Debido Proceso Legal (DPLF) y Comisión Mexicana de Defensa y Promoción de los Derechos Humanos A.C. (CMDPDH).

PERIÓDICO OFICIAL (P. 0). (2013). Ley de Ejecución de las Consecuencias Jurídicas del Delito del Estado de Sinaloa. [En línea]. Recuperado de http://www.transparenciasinaloa.gob.mx/images/stories/ARCHIVOS\%20PUBLICOS/Leyes $\% 20$ Estatales $\% 20$ Actuales/2011/ley_consecuencias_juridicas.pdf

Principios y Buenas Prácticas sobre la Protección de las Personas Privadas de Libertad en las Américas. (2008). [En línea] Recuperado de www.oas.org/es/cidh/mandato/Basicos/ PrincipiosPPL.asp. Washington: OEA.

REAL ACADEMIA ESPAÑOLA (RAE). Diccionario de la lengua española. (2018). [En línea]. Disponible https://dle.rae.es/?id=UCpprON

Reglas de las Naciones Unidas para el tratamiento de las reclusasy medidas no privativas de la libertad para las mujeres delincuentes (Reglas de Bangkok, 2011). Tailandia:UNODC. [En línea] Recuperado enhttps://www.unodc.org/documents/justice-and-prisonreform/Bangkok_Rules_ESP_24032015.pdf

Reglas Mínimas de las Naciones Unidas para el Tratamiento de los Reclusos (Reglas Nelson Mandela, 2015). Alemania: UNODC. [En línea] Recuperado defile:///F:/MUJERES\%20E\%20HIJOS\%20EN\%20PRISIÓN/REGLAS\%20MANDELA,\%20P.\%209.pdf

RICH, ADRIENNE (1977). Of Woman Born. Motherhood as experience and institution. London: Virago.

RISSO, MARIANA (2016). Maternidad y Prisión: Líneas para pensar el encierro Femenino, en: El tiempo quieto. Mujeres privadas de libertad en Uruguay, Montealegre, Natalia; Sapriza, Graciela y Folle, María (compiladoras).

SALETTI- CUESTA, LORENA (2008). «Propuestas teóricas feministas en relación al concepto de maternidad». En Revista Estudio de género y teoría feminista 7:169-184. [En línea"] Recuperado en http://dialnet.unirioja.es/servlet/articulo?codigo $=2884595$ SALINAS, CLAUDIA. (2014).Las cárceles de mujeres en México: espacios de opresión patriarcal. en Revista de Ciencias Sociales de la Universidad Iberoamericana. Año IX, No. 117. Enero-Junio de 2014. [En línea] Recuperado de file:///F:/MUJERES\%20E\%20HIJOS\%20 EN\%20PRISIÓN/1_CLAUDIA_SALINAS_NOTAS_PARA_ELDEBATE_N017.pdf

STAKE, ROBERT (1995). Investigación con estudios de casos, Madrid: Morata,

TAYLOR, STEVEN y BODGAN ROBERT (1987). Introducción a los métodos cualitativos de investigación, Buenos Aires: Paidós.

WACQUANT, LOÏC (1999). Las cárceles de la miseria. Francia: Raisons d'agir.

WORLD PRISON BRIEF (2018). World Prison Population List. Institute for Criminal Policy Research: University of London. 